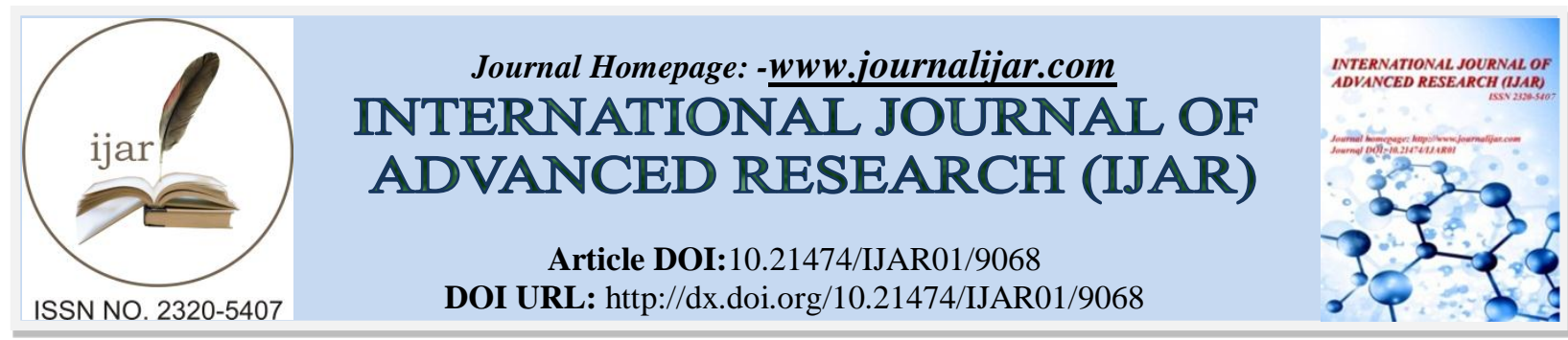

RESEARCH ARTICLE

\title{
RESIDENT'S KNOWLEDGE, ATTITUDES AND PATTERNS OF USE TOWARDS COMPLEMENTARY AND ALTERNATIVE MEDICINES (CAM).
}

\author{
Gilbert Anthony O. Abaño, RN, MAN and Joel D. Maraviles, LPT, Med.
}

Faculty of Education, Eastern Visayas State University- Ormoc City Campus, Ormoc City, Leyte-PHILIPPINES 6541.

\section{Manuscript Info}

Manuscript History

Received: 14 March 2019

Final Accepted: 16 April 2019

Published: May 2019

\section{Key words:-}

Knowledge, Attitudes, Patterns of Use, Alternative, Complementary Medicines, Upland Ormoc.

\begin{abstract}
Complementary and Alternative Medicines (CAM) has soared significantly in the recent years and current evidence suggest that there is a widespread trend for decades. This study intended to discern the knowledge, attitudes, and patterns of use towards the use of CAM. The study utilized a quantitative descriptive survey design and relevant data to the aforementioned aims were collected through self-made questionnaires from the barangays of Cabintan $(n=47)$, Lake Danao $(n=50)$, Tongonan $(n=29)$, Patag $(n=46)$ respectively and all were located in the highlands of Ormoc. Eleven classifications of CAM were listed as utilized by the respondents. Leaf extract (decoction), traditional or conventional massage (hilot), and Herbal medicine/tablets were the most conventional types of CAM across all studied areas, contributing 68\% $(n=117), 72 \% \quad(n=124)$, and $44 \% \quad(n=76)$ respectively. Moreover, their rampant usage was primarily due to the influence from friends or family members $(36 \%, \mathrm{n}=62)$ and they used it to treat health problems $(40 \%, \mathrm{n}=69)$. Amongst the diverse diseases equated with the use of CAM, cough $(72 \%, \mathrm{n}=124)$ and fever $(67 \%$, $\mathrm{n}=115$ ) were the most alleviated. Generally, most respondents displayed an overall positive attitude of all forms of CAM documented in this study in all of the surveyed barangays. Hence, present study recognizes that Complementary and Alternative Medicine plays a vital health care role amongst the residents in upland Ormoc.
\end{abstract}

Copy Right, IJAR, 2019,. All rights reserved.

\section{Introduction:-}

The CAM or also known as Complementary and Alternative Medicine or Modalities has been widely used worldwide by different medical professionals, herbalist, lay people and even indigenous tribes. CAM is defined as a different approach to health care with a history of use or practices that are not in the mainstream western medicine or standard medical care (National Center for Complimentary and Integrative Helath, 2014). A complementary therapy is generally used along with the standard medical treatment but are not considered to be standard. Alternative medicine on the other hand, are treatments that are used instead of standard medicine so it is imperative that health care providers and clients must know the risk factors associated with it. The NCCIH in 2014 has categorized Complimentary and Alternative Medicine (CAM) into 2 subgroups: Body and mind therapies and products that are deemed natural such as herbal products, botanicals, probiotics, minerals and vitamins where it is 
widely distributed and marketed in different pharmacies and stores and can easily be identified as dietary supplements.

The World Health Organization in 2000 has noted an increase in the use of various forms of CAM in developing countries as their primary health care practice for years and has shown a significant expansion worldwide in countries where the use of conventional or western medicine is predominant ${ }^{(1)}$. Several literatures were published connoting that the utilization of CAM is widespread in most developing countries which includes Africa (Matheka \& Demaio 2013; McFarlane, 2015), India (Sing et al., 2004; Roy et al., 2015), Malaysia (Lee et al., 2007; Sivadasan et al., 2014) and Mexico (Valenzuela-Atelo et al., 2011; Marshnik et al., 2016). This

Several studies reveal that different factors have influenced the restored interest in the use of CAM in the Philippines like the social, economic and political factors to name a few. In the Philippine setting, traditional medicine has been practiced since ancient times and its evolution is an interesting subject that is influenced by mysticism, religion, folklore, magic and superstition. The most common traditional medicine practitioner is called the hilot or manghihilot which then acts as midwives, and a chiropractor or a massage therapist that is believed to promote healing and health among residents in the rural areas. The increasing interest of the CAM modalities in developing countries such as the Philippines evinced that CAM is considered to be a vital aspect of public health care in the country.

Furthermore, the expensive cost of administering traditional western medicines, which is beyond reach and unsympathetic to families who belong to the marginalized sector of the society and to those people living in the country-side has also been found responsible for this trend. Regardless of the countless literatures published reporting on the significant use of CAM modalities in different countries, there is still scantiness of relevant information and statistical data on the usage of this modality, specifically the knowledge, attitudes and patterns of use of the people living in the upland areas of Ormoc City, Leyte, Philippines. This study is therefore initiated to bridge the gap in knowledge.

\section{Methodology:-}

The study utilized a quantitative descriptive survey design. This was the most appropriate design for this particular study because it allowed for a wide variety of in-depth data to be collected and analyzed regarding the subject of the research. This allowed the researcher to understand the topic better in order to provide opportunities for further studies. It also provided great detail about the studied concepts and did not manipulate variables or administer an intervention. The study was carried out in the upland barangays of Ormoc City namely: Tongonan, Cabintan, Lake Danao, and Patag. A total of 180 respondents. An average of 47 participants from each barangay were intentionally selected.

The researchers utilized a self-made questionnaire adopted from the study of Ching, Flores \& Acelajado (2016) with slight modification of some of the parameters to congregate comprehensive data pertinent to the respondent's degree of attitudes, knowledge and patterns of use towards CAM. The procedure was duly assented by the Ethical Research Committee of EVSU - Ormoc Campus and the informed consent form was secured from the residents who were amenable to participate in the survey preceding the data collection.

The self-made questionnaires were shared out to the respondents and those participants needing support with regards to content comprehension and filling-out the survey form were facilitated by the assigned research assistants. The completed survey forms were reclaimed by the proponent two weeks after handing out and dissemination. Subsequently, a focus group discussion or FGD and face to face interviews were organized to cluster pertinent information that may not have been expressed by the respondents.

The researcher utilized descriptive statistics such as frequencies and percentages. A comparison technique was utilized to explore specific data collated across all the studied barangays. Moreover, the researchers used a Likert scale to assess the attitude of the residents towards Complimentary and Alternative Medicines, with $4=$ denoting as very strong and 1 denoting a very weak response. 


\section{Results And Discussion:-}

A total of 172 participants with ages 15 years old and above from the selected barangays in Ormoc City revealed that they make use of Complementary and Alternative Medicines, thus implying that this kind of modality is universally recognized amongst all age brackets in the areas studied. In terms of the gender of the respondents, male $(35 \%, \mathrm{n}=60)$ and female $(65 \%, \mathrm{n}=112)$, the numbers are not from each other. There were $114(66 \%)$ of the respondents whose educational attainment are up to high school or elementary, and 58 (34\%) with college or graduate level. The distribution of the participants to this study into different categories is a good indicator to gather the common knowledge, attitude, and patterns of use about CAM. This also buttresses the common perception that most CAM users obtained lower educational qualifications.

\section{Different Cultural Traditions}

Table 1:-Different cultural traditions that influenced the decisions about health care of the residents from selected places in Ormoc City.

\begin{tabular}{|l|l|l|l|l|}
\hline \multicolumn{2}{|l|}{ Cultural Traditions (\%) } & \multicolumn{2}{l|}{ Barangay } \\
\hline & Cabintan & Lake Danao & Tongonan & Patag \\
\hline & $\boldsymbol{n = 4 7}$ & $\boldsymbol{n = 5 0}$ & $\boldsymbol{n = 2 9}$ & $\boldsymbol{n = 4 6}$ \\
\hline Chinese & - & 14 & - & 11 \\
\hline Western Culture & - & - & - & 4 \\
\hline Bicolano & - & 2 & 3 & - \\
\hline Cebuano/Bisaya & 100 & 78 & 97 & 80 \\
\hline Tagalog & - & 26 & - & 9 \\
\hline Waray & - & - & - & 22 \\
\hline No Influence & - & - & - & 4 \\
\hline
\end{tabular}

Table 1 shows that all four barangays were influenced by Cebuano/Bisaya traditions on their decisions regarding the use of CAM. The overall percentage for the upland city is reflected in figure 1. The graph dislplays that Cebuano/Bisaya tradition is the most influencial with $88 \%(\mathrm{n}=151)$ of all the respondents. This result elucidated that almost all the people in Ormoc City and its connected municipalities within Leyte are cebuano/bisaya.

Figure 1:-Over all cultural traditions that influenced the decisions about health care of the residents from selected places in Ormoc City.

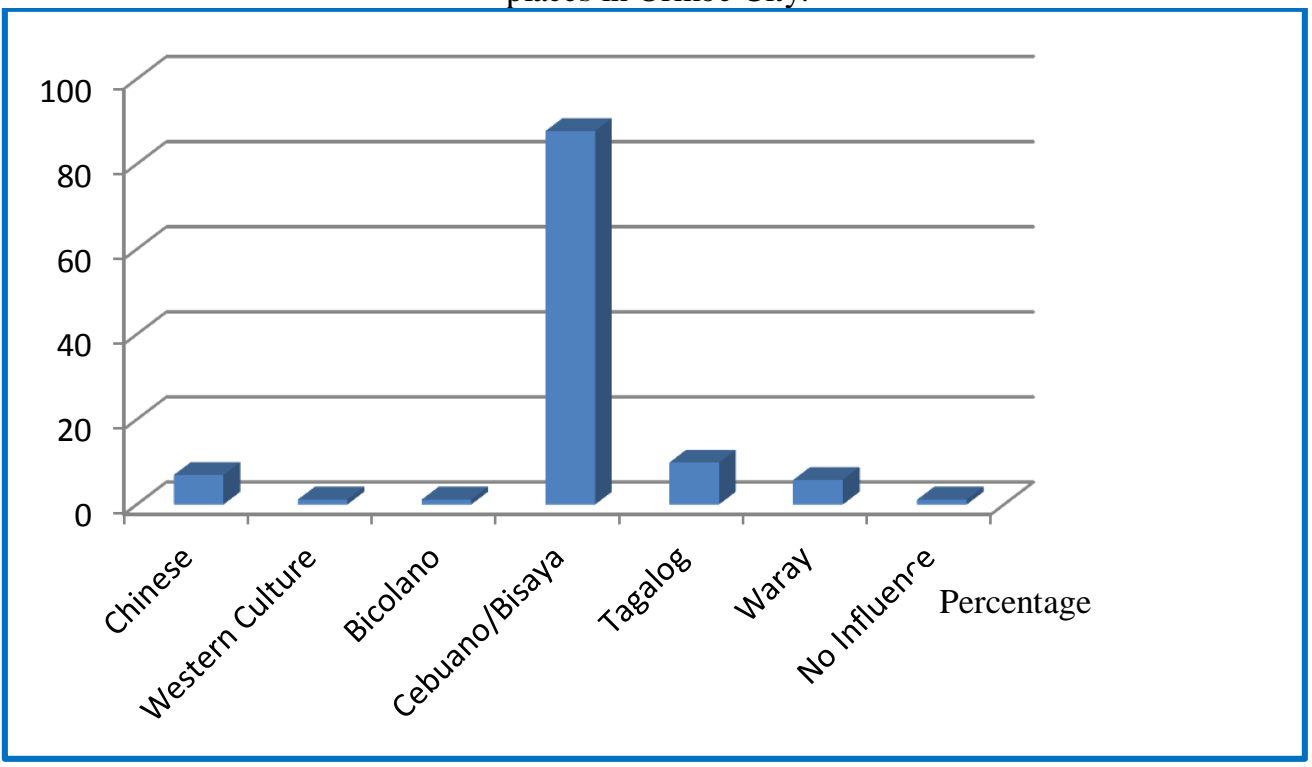




\section{Different Religious Traditions}

Table 2:-Different religious traditions that influenced the decisions about health care of the residents from selected places in Ormoc City.

\begin{tabular}{|l|l|l|l|l|}
\hline \multicolumn{2}{|l|}{ Religious Traditions (\%) } & Barangay & \\
\hline & Cabintan & Lake Danao & Tongonan & Patag \\
\hline & $\boldsymbol{n = 4 7}$ & $\boldsymbol{n = 5 0}$ & $\boldsymbol{n = 2 9}$ & $\boldsymbol{n}=\mathbf{4 6}$ \\
\hline Roman Catholic & 100 & 86 & 100 & 67 \\
\hline $7^{\text {th }}$ Day adventist & - & 8 & - & 9 \\
\hline Church of God & - & - & - & 2 \\
\hline Born again & - & 8 & - & 9 \\
\hline Iglesia Ni Kristo & - & - & - & 2 \\
\hline No Influence & - & - & - & 9 \\
\hline
\end{tabular}

Table 2 shows that all four barangays were influenced by Roman Catholic traditions on their decisions regarding the use of CAM. The overall percentage for the upland city is reflected in figure 2. The graph dislplays that Roman Catholic tradition is the most influencial with $87 \%(\mathrm{n}=150)$ of all the respondents. This statistic has a positively high correlation with the religion of the residents of Ormoc City, Leyte with a very high percentage. Since most of the residents in Ormoc City are Roman Catholic, then most of the residents are influenced by Roman Catholic traditions.

Figure 2:-Over all religious traditions that influenced the decisions about health care of the residents from selected places in Ormoc City.

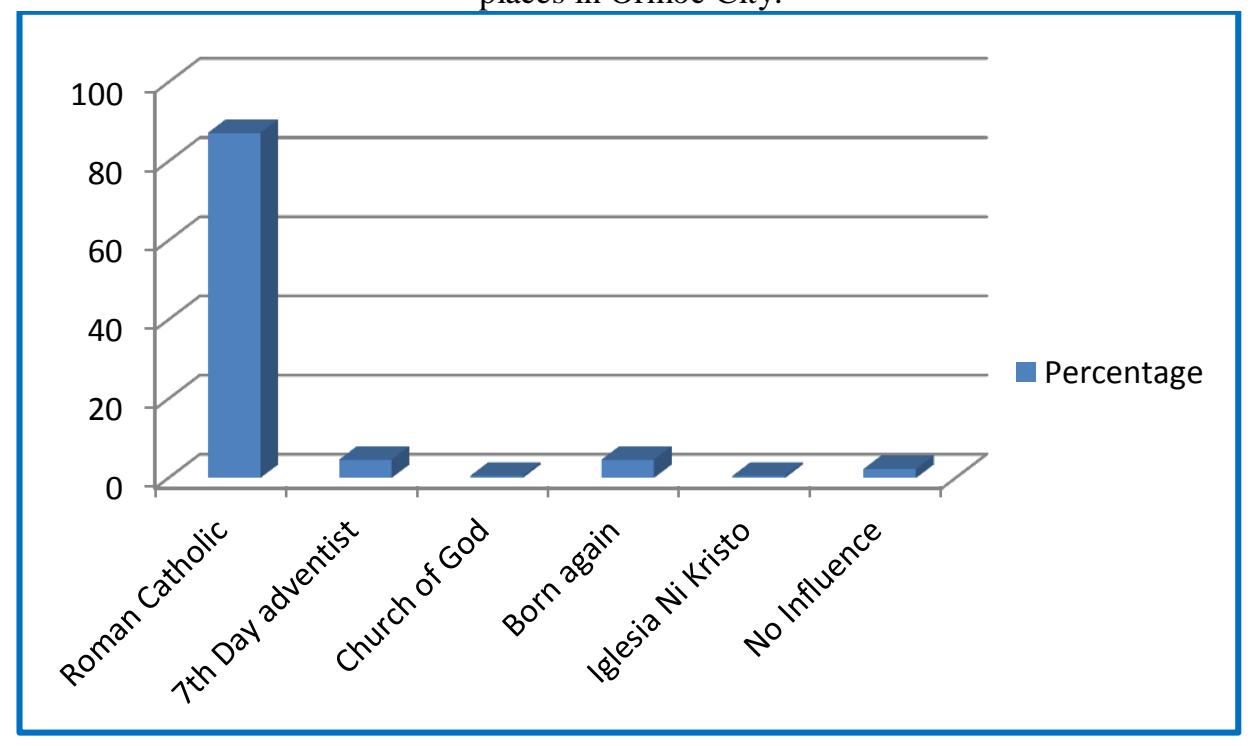

\section{Different Usage of CAM}

Table 3:-Different usage of complementary alternative medicine (CAM).

\begin{tabular}{|l|l|l|l|l|}
\hline Usage of CAM (\%) & Barangay & & \\
\hline & Cabintan & Lake Danao & Tongonan & Patag \\
\hline preventing illness & $\mathbf{n = 4 7}$ & $\boldsymbol{n = 5 0}$ & $\boldsymbol{n = 2 9}$ & $\boldsymbol{n = 4 6}$ \\
\hline treating illness & 9 & 20 & 31 & 28 \\
\hline promoting health & 91 & 80 & 86 & 76 \\
\hline I have $\boldsymbol{n e v e r}$ used CAM & 4 & 4 & 38 & 11 \\
\hline
\end{tabular}

The selected barangays of Ormoc City have a high percentage of respondents who used CAM in treating ailments. The details are displayed in table 3. Generally, in figure 3, treating ailments (top 1) has 83\% ( $\mathrm{n}=143$ ) of the respondents. 
Figure 3:-Over all usage of complementary alternative medicine (CAM).

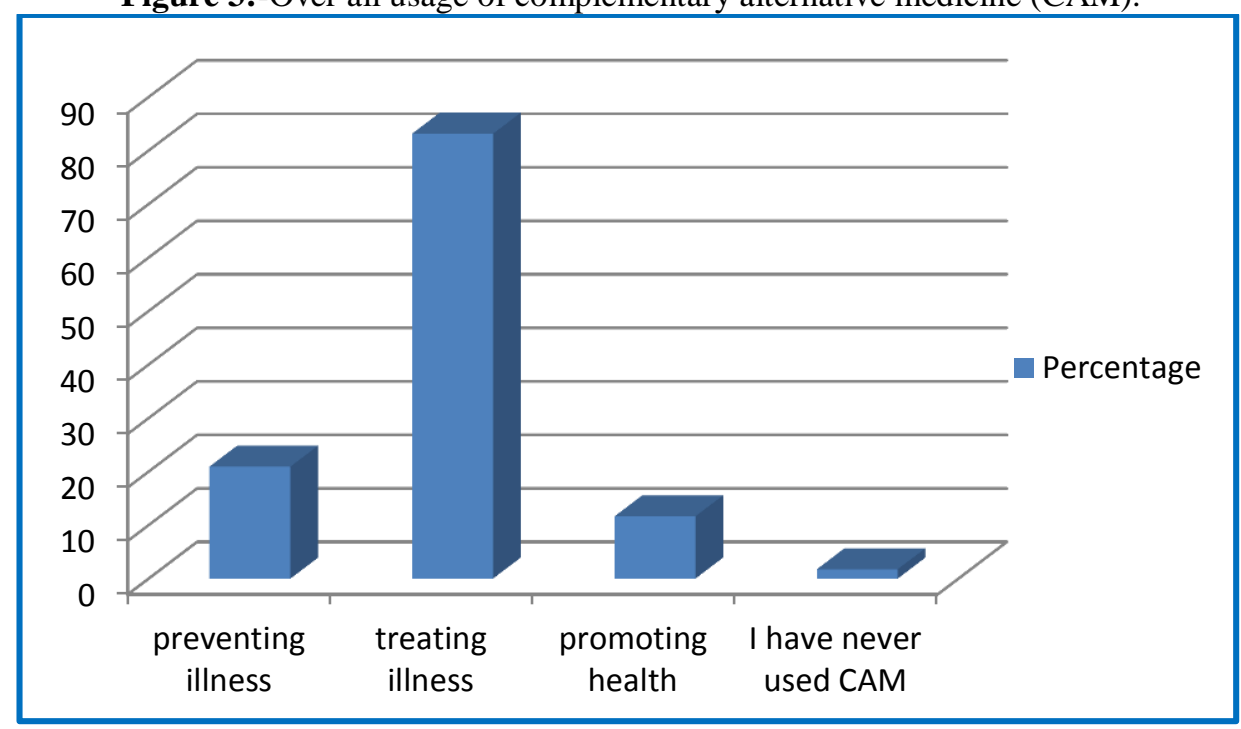

Different Forms of CAM

Table 4:-Different natural health products and therapies used by the residents from selected places in Ormoc City.

\begin{tabular}{|c|c|c|c|c|}
\hline \multicolumn{2}{|l|}{ Forms of CAM (\%) } & \multirow{2}{*}{$\begin{array}{l}\text { Barangay } \\
\text { Lake Danao } \\
\end{array}$} & \multirow[b]{2}{*}{ Tongonan } & \multirow[b]{2}{*}{ Patag } \\
\hline & Cabintan & & & \\
\hline & $n=47$ & $n=50$ & $n=29$ & $n=46$ \\
\hline Art therapy & 6 & 10 & - & 7 \\
\hline Leaf Extract/Decoction & 87 & 50 & 69 & 67 \\
\hline Traditional Massage/HILOT & 87 & 58 & 90 & 61 \\
\hline Herbal medicine/tablets & 49 & 62 & 3 & 46 \\
\hline Spiritual Healing & 4 & 12 & 41 & 39 \\
\hline Plastering of leaves & 2 & 10 & 17 & 28 \\
\hline Prayers and Murmuring & 2 & 14 & 52 & 20 \\
\hline Reflexology & 2 & 8 & 7 & 11 \\
\hline Relaxation/Breathing technique & - & 10 & - & 7 \\
\hline Vitamins and minerals & 30 & 22 & 7 & 20 \\
\hline Yoga & - & - & 28 & 4 \\
\hline
\end{tabular}

Based on the survey conducted, there were 11 recorded as the most traditional forms of CAM utilized by the respondents. Among these 11, Traditional Massage/HILOT and Leaf Extract/Decoction are the most traditional types of CAM utilized by the upland residents. Table 4 reveals the detailed distribution of responses.

The overall responses were recorded too and is presented in figure 4. Leaf Extract/Decoction has 68\% ( $\mathrm{n}=117)$ and Traditional Massage/HILOT has $72 \%(\mathrm{n}=124)$. Only these forms of CAM have more than $50 \%$ of the respondents used these. This conclusion is relatively in parallel with previously published work in the Philippines by the following researchers: Ching et al. (2016) Salibay et al. (2007) and Arsenio et al. (2011). Moreover, a homogenous study conducted in Pakistan disclosed similar results to current study which was led and administered by Shaikh et. al. (2008). Contrary to similar reports in the review of literature, a survey conducted in Australia, Bensoussan (2004) disclosed acupuncture as the most widely used form of CAM. This discrepancy is imputed to the disparity in understanding of the preferred type of Complementary and Alternative Medicines amongst the Filipinos and Australians. 
Figure 4:-Over all natural health products and therapies used by the residents from selected places in Ormoc City.

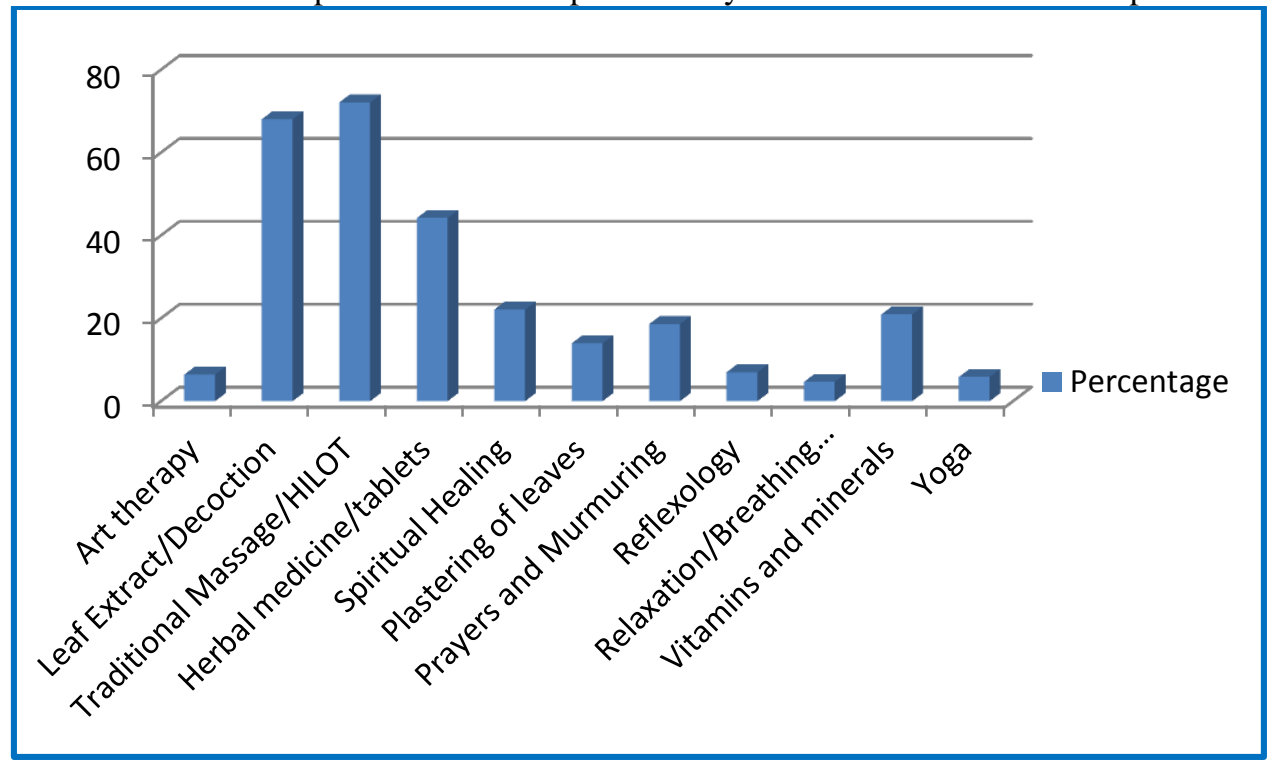

Reasons for Using CAM

Table 5:-Different reasons why the residents from selected places in Ormoc City used CAM.

\begin{tabular}{|c|c|c|c|c|}
\hline \multicolumn{2}{|l|}{ Reasons for Using CAM (\%) } & \multirow{2}{*}{$\begin{array}{l}\text { Barangay } \\
\text { Lake } \\
\text { Danao }\end{array}$} & \multirow[b]{2}{*}{$\begin{array}{l}\text { Tongona } \\
\text { n }\end{array}$} & \multirow[b]{2}{*}{$\begin{array}{l}\text { Pata } \\
\text { g }\end{array}$} \\
\hline & $\begin{array}{l}\text { Cabinta } \\
\text { n }\end{array}$ & & & \\
\hline & $n=47$ & $n=50$ & $n=29$ & $n=46$ \\
\hline 1. CAM is recommended by medical practitioner & - & 12 & 10 & 4 \\
\hline 2. CAM is recommended by friends or family & 38 & 40 & 31 & 33 \\
\hline 3. CAM is used to treat health problems & 57 & 26 & 48 & 33 \\
\hline 4. CAM is natural and therefore safer & 23 & 18 & 14 & 26 \\
\hline 5. CAM is used for the maintenance of general health & 2 & 8 & 41 & 15 \\
\hline $\begin{array}{l}\text { 6. CAM is used because many are dissatisfied with conventional } \\
\text { medicine }\end{array}$ & - & 14 & 7 & 17 \\
\hline 7. CAM is used because conventional medicines are expensive & 6 & 8 & 14 & 24 \\
\hline
\end{tabular}

From table 5, it can be noticed that the four barangays have common reasons of using CAM. The respondents were persuaded to use CAM by their friends and family and for an expected reason; they are using it to treat health problems. Those are the top two reasons why they use CAM. The figure below (5) shows the overall comparison of the responses. There were $36 \%(\mathrm{n}=62)$ of the respondents who used CAM because of the recommendation by family or friends and $40 \%(n=69)$ in order to treat health problems. This result is somehow in line with the study of Ching et al. (2016) with almost 30\% and almost 25\% respectively as his top 2 and top 3 reasons. The top 1 reason (Recommended by Medical Practitioner) reported from Ching et al. (2016) is completely in contradiction to this study with the least percentage as shown in the graph below. 
Figure 5:-Over all reasons why the residents from selected places in Ormoc City used CAM.

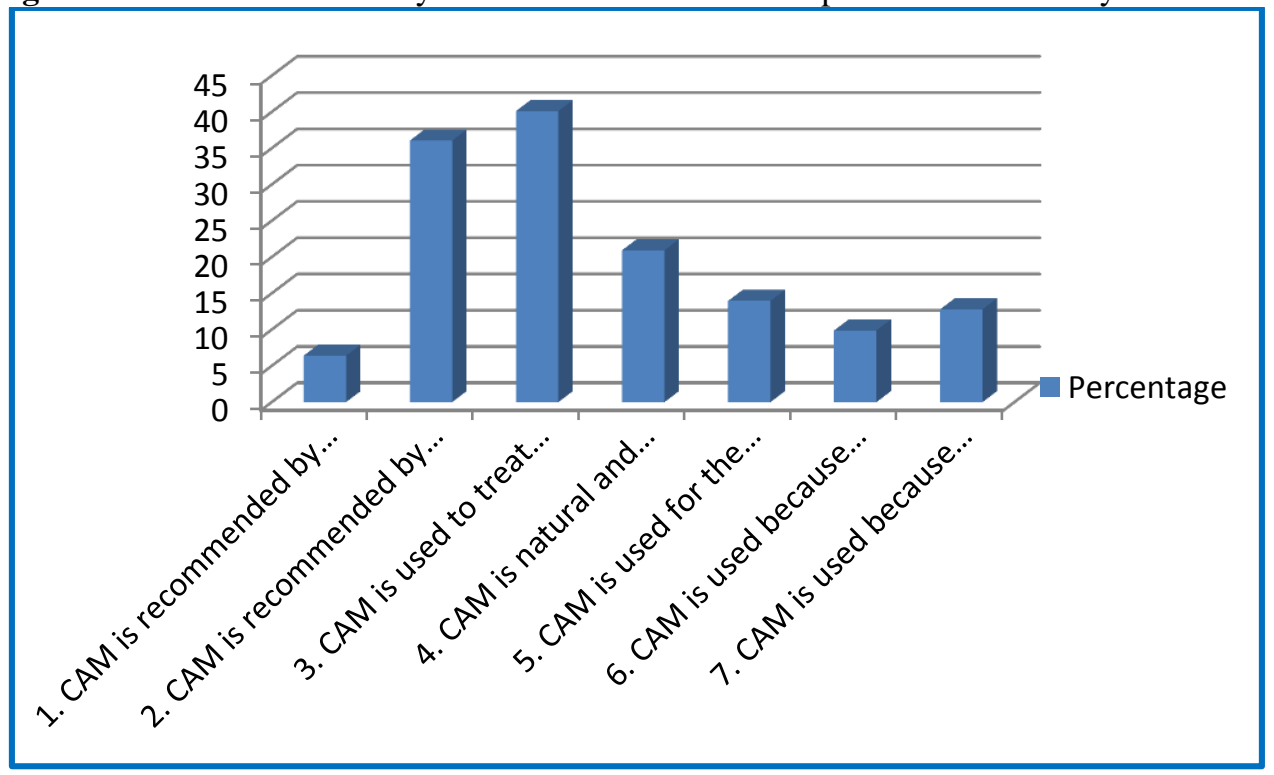

Ailments Associated with CAM

Table 6:-Different ailments associated with CAM usage.

\begin{tabular}{|l|l|l|l|l|}
\hline \multicolumn{2}{|l|}{ Ailments Associated with CAM Usage (\%) } & Barangay & & \\
\hline & Cabintan & Lake Danao & Tongonan & Patag \\
\hline common colds & $\boldsymbol{n = 4 7}$ & $\boldsymbol{n = 5 0}$ & $\boldsymbol{n = 2 9}$ & $\boldsymbol{n = 4 6}$ \\
\hline cough & 34 & 36 & 62 & 54 \\
\hline fever & 91 & 70 & 72 & 54 \\
\hline flu & 79 & 60 & 76 & 57 \\
\hline high blood pressure & 21 & 18 & 55 & 33 \\
\hline muscle pains & 36 & 26 & 41 & 30 \\
\hline diabetes & 21 & 26 & 41 & 35 \\
\hline abdominal pains & 13 & 8 & 45 & 22 \\
\hline asthma & 81 & 38 & 38 & 33 \\
\hline burns & 15 & 12 & 7 & 24 \\
\hline skin diseases & 21 & 16 & 14 & 30 \\
\hline UTI & 21 & 16 & 24 & 39 \\
\hline diarrhea & 68 & 26 & 7 & 24 \\
\hline & 81 & 46 & 10 & 46 \\
\hline
\end{tabular}

Among the 13 recorded ailments in table 6 , the four barangays had 1 in common to be the top ailment associated with CAM usage - the cough.

The top two disorders recognized by the residents in relation to Complementary and Alternative Medicine were fever and cough. This result is in contrast with the study previously determined by Ching et al. (2016), Shaikh et al. (2008) in Pakistan and Arsenio et al. (2011) in Philippines, both disclosing fever and cough are the recurring top ailments medicated and treated with CAM. Figure 6 displays the overall comparison among the 13 ailments. 
Figure 6:-Overall ailments associated with CAM usage.

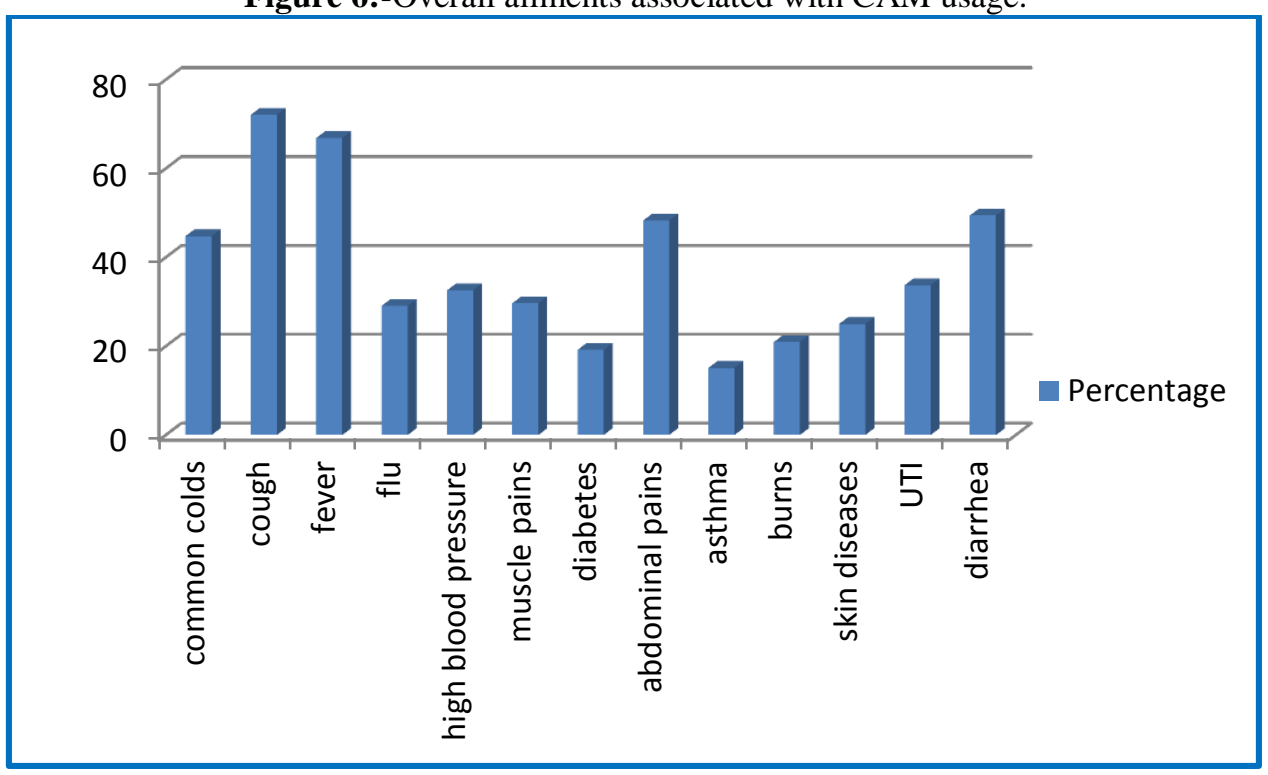

Herbal Plants Used to Treat Ailments

Table 7:-Different herbal plants used to treat ailments by residents from selected places in Ormoc City

\begin{tabular}{|l|l|l|l|l|}
\hline Herbal Plants Used to Treat Ailments (\%) & Barangay & & \\
\hline & Cabintan & Lake Danao & Tongonan & Patag \\
\hline & $\boldsymbol{n = 4 7}$ & $\boldsymbol{n = 5 0}$ & $\boldsymbol{n = 2 9}$ & $\boldsymbol{n}=\mathbf{4 6}$ \\
\hline Luy-a & 36 & 32 & 24 & 39 \\
\hline Tawa-Tawa & 87 & 64 & 21 & 37 \\
\hline Ahos & 28 & 30 & 3 & 41 \\
\hline Herba Buena (Kalabo, Klavo) & 87 & 78 & 21 & 46 \\
\hline Aloe Vera & 34 & 32 & 21 & 43 \\
\hline Duwaw & 38 & 30 & 24 & 41 \\
\hline Kamunggay & 26 & 44 & 48 & 48 \\
\hline Lagundi & 26 & 34 & 21 & 52 \\
\hline Dahon sa Bayabas & 70 & 46 & 28 & 59 \\
\hline Akapulko & 19 & 16 & 14 & 22 \\
\hline Banaba leaves & 57 & 34 & 59 & 22 \\
\hline Dahon sa Kapayas & 91 & 52 & 38 & 33 \\
\hline Ampalaya & 6 & 16 & 7 & 22 \\
\hline
\end{tabular}

There are 13 herbal plants listed as being used by the respondents to treat ailments. Table 7 is the comparison among the four barangays under this study. Based on the table, the barangays of Ormoc City such as Cabintan, Lake Danao, Tongonan, and Patag all have different herbal plants to be their commonly used to treat ailments. Their top herbal plants are dahon sa kapayas (91\%), herba buena/kalabo (78\%), banaba leaves (59\%) and dahon sa bayabas (59\%), respectively. The variation could be due to the availability of plants to the respective places.

In figure 7 , herba buena/kalabo ( $62 \%, \mathrm{n}=107$ ) is the top herbal plant commonly used by the combined respondents. 
Figure 7:-Over all herbal plants used to treat ailments by residents from selected places in Ormoc City

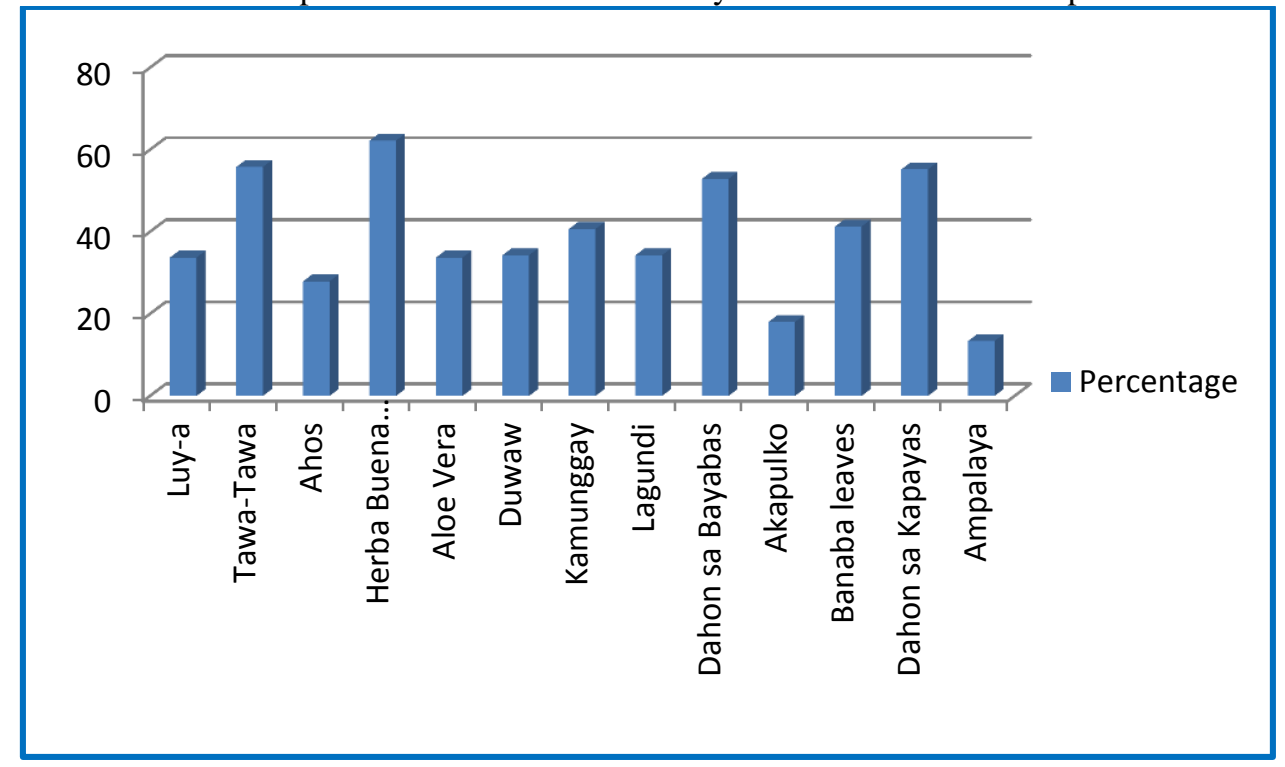

Attitude Towards CAM

Table 8:-Different attitudes towards CAM of the residents from selected places in Ormoc City

\begin{tabular}{|l|l|l|l|l|l|}
\hline Attitude Towards CAM (\%) & & & Barangay & & \\
\hline & Cabintan & Lake Danao & Tongonan & Patag & Upland Ormoc City \\
\hline & $n=47$ & $n=50$ & $n=29$ & $n=46$ & $n=170$ \\
\hline Strongly agree & 1 & 6 & 7 & 29 & 11 \\
\hline Agree & 91 & 85 & 93 & 58 & 81 \\
\hline Disagree & 6 & 9 & 0 & 11 & 7 \\
\hline Strongly Disagree & 1 & 1 & 0 & 2 & 1 \\
\hline Overall scale & 2.93 & 2.95 & 3.07 & 3.13 & 3.01 \\
\hline Interpretation & Agree & Agree & Agree & Agree & Agree \\
\hline
\end{tabular}

Respondents residing in the barangay of Cabintan, Lake Danao, Tongonan and Patag in upland Ormoc City answered positively towards CAM utilization, revealing a mean range of 2.93 to 3.13 which has a striking elucidation of agree.

Table 8 revealed that, generally residents from upland Ormoc City concurred on the utilization of Complementary and Alternative Medicines, showing a mean average score of 3.01. This further indicated that the behavior of the community towards CAM modalities have incredibly transformed positively. Moreover, it revealed that these kind of modalities are turning progressively tolerable and reasonable amongst the respondents in the studied areas. The determined positive attitudes and behavior demonstrated by the upland residents in the recent study towards CAM utilization is strongly attributed to the belief of the effectiveness of different types of these modalities for prevention and remedy of the mainstream illnesses identified in their community.

\section{Conclusion:-}

Apparently, Traditional Massage (HILOT) and leaf extract/decoction appeared to be the most prevailing form of CAM utilized by the study respondents. This holds true to all the barangays in upland Ormoc. The ramification of this research further revealed that the surveyed respondents were mostly influenced by their belief that the utilization of these modalities will treat their health problems. Respondents were further influenced by Bisaya/Cebuano culture and Roman Catholicism appeared to have greatly influence them in CAM utilization.

The preeminent indisposition treated with CAM in upland Ormoc encompasses cough and flu. Overall, the medicament used to treat these common ailments were mainly prepared by herbal medicine concoctions which includes "Herba Buena", "Dahon sa Kapayas", "Dahon sa Bayabas" and "Banaba leaves". The four barangays 
representing upland Ormoc responded positively in the use of CAM. Over all, the survey revealed a positive attitude towards Complementary and Alternative Medicines among the respondents which shows an over all rating of 3.01 and is elucidated as strong.

\section{References:-}

1. Bensoussan A, Myers SP, Wu SM, O’Connor K (2004) Naturopathic and Western herbal medicine practice in Australia: A workforce survey.Complementary Therapies in Medicine 12:17-27. DOI:http://dx.doi.org/10.1016/j.ctim.2004.01.001.

2. Ching A, Flores R, Acelajado M, (2016) Complementary and Alternative Medicines Among Residents in upland Cavite, Philippines: Their Knowledge, Patterns of Use and Attitudes. Jounral o Experimental Biology and Agricultural Science. 4(2): 2-9.

3. Erasto P, Majinda RRT (2011) Bioactive proanthocyanidins from the root bark of Cassia abbreviata. International Journal of Biological and Chemical Sciences 5(5): 2170-2179. doi: http://dx.doi.org/10.4314/ijbcs.v5i5.36

4. Erasto P, Adebola PO, Grierson DS, Afolayan AJ (2005) An ethnobotanical study of plants used for the treatment of diabetes in the Eastern Cape Province, South Africa. African Journal of Biotechnology 4:1458 1460 .

5. Furnham A (2000) Attitudes towards homoeopathy in particular and beliefs about complementary medicines in general. Psychology, Health and Medicine 5: 327 -342. DOI:10.1080/713690198

6. Marshik PL, Kharat AA, Jakeman B, Borrego ME, Dodd MA, Bachyrycz A, Anderson JR, Bond R, Deming P, Mercier R, Nawarskas JJ, Ray G, Salazar K (2016) Complementary and Alternative Medicine and Therapy Use in a Diverse New Mexican Population. Journal of Alternative \& Complementary Medicine22: 1, 45 - 51. DOI:

7. 10.1089/acm.2014.0378.

8. Mc Farlane C (2015) South Africa: The Rise of Traditional Medicine. Insights on Africa 7: 60 - 70 . doi: $10.1177 / 0975087814554070$.

9. Roy V, Gupta M, Ghosh RK (2015) Perception, attitude and usage of complementary and alternative medicine among doctors and patients in a tertiary care hospital in India. Indian Journal of Pharmacology 47: 2, 137 - 142. DOI: $10.4103 / 0253$ - 7613.153418

10. Shaikh SH, Malik F, James H, Abdul H (2008) Trends in the use of complementary and alternative medicine in Pakistan: a population - based survey. Journal of Alternative and Complementary Medicine 15: 545 - 550.

11. doi: 10.1089/acm.2008.0232.

12. Singh V, Raidoo DM, Harries CS (2004) The prevalence, patterns of usage and people's attitude towards complementary and alternative medicine (CAM) among Indian community in Chatsworth, South Africa. BMC Complementary and Alternative Medicine 4:1 - 7. DOI: 10.1186/1472 - 6882 - 4-3. 